\title{
Gamification for Teaching and Learning Java Programming for Beginner Students - A Review
}

\author{
Jaouja Maiga ${ }^{1}$, Andi Wahju Rahardjo Emanuel ${ }^{2 *}$ \\ ${ }_{1}^{1}$ Magister Teknik Informatika, Universitas Atma Jaya Yogyakarta, Indonesia. \\ 2Jl. Babarsari no. 42, Sleman, DIY, Indonesia. \\ * Corresponding author. Tel.: +62274487711; email: andi.emanuel@uajy.ac.id \\ Manuscript submitted June 14, 2019; accepted August 12, 2019. \\ doi: $10.17706 /$ jcp.14.9.590-595
}

\begin{abstract}
Gamification is the use of game-design elements and game principles in non-game contexts. Nowadays, gamification becomes a new method used in teaching and learning programming concepts. The fundamental target of gamification is to increase motivation, experience and engagement which leads to fun and delight for students. Most early students have difficulties to understand the concept of Oriented Object Programming (OOP) in Java. This paper shows that Gamification as new trend can be used to solve the above problem by helping learners become very enthusiast and it provides the platform for them to be creative. This paper aims to give an overview of gamification in learning context which can help students to attempt learning Java programming Language. Being aware of the vulnerability of programming language mainly Java by using game as fun activity. Data in this study is based on a qualitative analysis of documents such as journals, books and the like. The result proved that gamification can be implemented to motivate and encourage learners to improve their skills in computer programming because gamification in education makes learners to be more fun and facilitates understanding of the coursework.
\end{abstract}

Key words: Gamification, teaching, learning, java programming, beginner students.

\section{Introduction}

Development and prevalence in recent years. Gamification has been characterized in [1] as "the use of game design elements in non-game contexts". Gamification uses the philosophy, elements, and mechanisms of game design in non-gaming environments to enhance user motivation and engagement in a particular task. In other words, gamification has the characteristics that can make real games fun and attractive and uses them to enhance the player's experience in a non-game environment, such as school, workplace, etc. [2].

It has proven to be a challenging task to teach computer programming skills in a university [3]. IT teachers have expressed growing concern about the challenges facing beginners, learning the programming principles [4]. Research has discovered that even following 2 years of learning programming, most beginner developers are as yet attempting to be proficient [5].

To attain the skills and knowledge needed for Java programming learning gamification which is the use of game elements in non-gaming environment context, gamification can be used to motivate users, solve problems, increase user experience and encourage desired behaviors [2].

Most beginner students have difficulties to understand the concept of Oriented Object Programming (OOP) in Java. This study is focused on gamification in java programming language to be useful to learners. 
It aims to give an overview of gamification which can handle beginner students to effort learning java programming language.

\section{Literature Review}

This chapter clarifies the gamification in a general view, the relationship between gamification and learning, programming learning problem, elements of gamification designing in details. Indicating progression and performance are the goals of using points scoring (game element) and there are multiple ways to gain point including completing questions/tasks or defeating opponents [6].

In the field of education, there are no opponents. Therefore, the experience will have to come from accomplishing different tasks and questions.

\subsection{Programming Learning Problems}

There are many difficulties in the programming learning [10], for example:

- General Orientation: it relates with the introduction of program improvement that includes the reason in creating system and some effective projects as the positive consequences of the program advancement.

- Pragmatics: it relates with the aptitudes in doing examination, creating, testing etc.

Besides, computer learning is the early hindrances, including programming which is discovered when students attempt finishing some tasks in the equivalent time [8].

The Overgeneralization is characterized as students have tendency to observe some issues or condition through programming which cannot be changed and will in general make speculations. However, misapplication of relationship is depicted as a mental process in general where students will make portrayal from one idea by doing similarity aimed to make them simple in recalling and appreciating the idea [9].

\subsection{The Problem of Choosing the Initial Programming Language}

The choice of the first programming language is essential for learning programming. Despite the large number of programming languages, the choice of the first appropriate programming language remains difficult.

Thus, the choice of the first programming language is the most important aspect in planning basic courses in programming. The choice varies according to the basic learning of the beginners and their ability to understand the basic ideas of programming [10].

\subsection{Java Programming}

Java is a programming language of Oriented Object Programming (OOP). Java programming language consists of a Java compiler, Java virtual machine, and Java class libraries. The study of how to learn java programming is a part of educational psychology, learning theory, and pedagogy Learning Method. Learning is the ongoing process of transforming information and experience into knowledge. Human learning can be part of education, schooling or training [10]. Below is a diagram of Java Learning method.

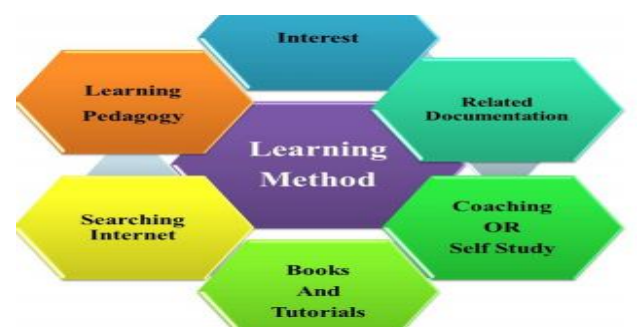

Fig. 1. Shows java learning method. 
The Fig. 1 shows that java learning is an accumulation of articulations that are gathered together to play an activity.

\subsection{Gamification towards Education Process}

The wide use of the term "Gamification" began in 2010. As a rule, this term is generally acknowledged and used to allude the use of game-based elements, such as game mechanics and game dynamics, in non-game environments to enhance users experience, motivation and engagement [11]. The use of Gamification in educational settings toward Java programming learning involves pedagogical approaches, methodologies, technical approaches. Game that consists of elements to facilitate students to learn faster and easier these elements include mechanical elements, such as incremental progression, and instant feedback; personal elements, such as status and visibility, collective responsibility, and leaderboards or rankings; and emotional elements, in particular the psychological state of flow.

Many students are unable to understand the programming language and for the lectures to teaching them. Therefore, gamification is a new tool that is used to encourage and motivate students to increase their engagement in learning. The gamification is a new method of learning used to teach programming concepts and there is no difference age or gender that means all people can enjoy learning [12]. Gamification can be applied in learning the normalization concept in database [13]. The model consists to divide the levels into stages and each level corresponds in a normal form. There are three stages in each level (easy, medium, and high) and gamification model aims to motivate and encourage students to improve their engagement in learning and then understanding normalization becomes easier.

\subsection{Achievements}

Achievements lead to another stream to indicate progress and they act as a rewarding mechanism. Achievements, despite being a common element to games, are not implemented in gamified systems as often as one might think [14]. An achievement consists of three elements: signifier, description, and completion criteria [15]. Generally, there are two types of achievements in both games and gamification applications. The first is the quantitative, or incremental achievements. These are managed by the application itself, as there is generally a numeric condition that a user needs to achieve in order to be awarded with the achievement. In games, these achievements can be about defeating an amount of enemies, reaching a level, or acquiring a certain amount of currency. Quantitative achievements are often progressive, starting with an easily achievable number and advancing to really further developers that are interested in participating in the project.

\subsection{Leaderboards}

While being one of the most implemented elements of gamification [14] the current literature suggests that Leaderboards actually do more harm than good and they are inherently a competitive element that is reported as harmful in education [16]. Providing an option of student anonymity to the instructor that will control whether the student names will be displayed or not in the leaderboards might decrease competitiveness and promote a better social comparison. Also, giving the students to opt-in or opt-out of leaderboards might be a good approach if they do not want anything to do with leaderboards, which will in turn give the students more autonomy that would potentially improve their intrinsic motivation [17].

This gap might never really tighten but at least, in many games, the new player would get a chance to improve their skills before getting thrown into the same arena as the experienced player. In Battlefield 4, Leaderboards are split into divisions so players would compete with their peers, from around the world, in terms of skill and in Clash Royal, only the top players can participate in the Leaderboards. The same thinking can be applied to gamification. If the students are made to compete from the first day, already 
experienced students will get an unfair advantage; especially when you consider that women do not enjoy competition as much as men do , this competition might become one-sided [18].

\subsection{Badges}

Badges are currently the most used reward elements in gamification [19]. They possess a powerful element as they contain both a visual and a textual element that provide a unique identification for accomplishments. Students should be able to show their badges on their profiles; or on a more general medium like forums or wiki pages; or on social media networks to receive recognition from their whole social circles. Badges, while simple, have an important aspect that should be taken into account and that is the significance of the visual aspect. If the badge given for a simple task looks rather similar, without any signifiers, to a badge that is given for a really tough task, it would not be very hard to imagine the latter badge to lose its significance.

\subsection{The Benefit of Gamification in Teaching}

Gamification is a method of encouragement and motivation. this method is used in the areas of education, learning and evaluation [20]. The integration of gamification in learning is easy and effective. [6] Gamification can be implemented in learning activities which motivates and engages students into friendly competitions environment with others learners. A new design of e-learning aimed at programming education for groups of students aimed to enable students to increase their engagement by not only awarding individual but also in teamwork. Gamification aims not only to improve students motivations and engagements, but also for their courage to participate in various activities and have fun [15], to understand through the systematic mapping study on gamification is the trends in the research area [21], gamification allowed automation teaching as the main advantages in gamification for the future of education is that it automates many of the tasks that would otherwise be performed by the teacher.

Achievement rewards are flexible to give more control to the instructor. Rewards are made of four options: attendance, grades, badges, and points. Rewards section has the possibility of rewarding the student multiple items [17].

\section{Related Work}

In this section, Gamification in GeNIE and Self-Determination Theory (SDT) researches discuss as the existing techonologies used in gamification. These technologies help students to learn programming.

There are many different game elements that can be used to gamify learning, and there is some skill determining which are appropriate for a particular group of learners and activity and which are not.

\subsection{Gamification in GeNIE}

GeNIE includes Points, Leaderboards, Badges and Achievements as its gamification element subset. As modularity is a key component, instructors are given switches that they can use to enable or disable each of these elements for a course and the functionality works in a semester basis so that the retrospective implementations of the settings would be kept within the system, and this switch is also provided for the gamification aspect in its totality. Once any of these switches are turned off, students lose their access to the given element [22].

However these switches are not only given to instructors, they are also given to students in which they can control their own settings. Students are given the options to enable or disable individual elements of gamification for a given course in a specific semester, which might in turn increase their feeling of autonomy and competence by not forcing anything on the students. First of the four implemented elements is Leaderboards, which often receives negative feedback due to the competitive environment it creates [16]. 
Multiple options to address this issue have been implemented in the platform; first of them, as mentioned earlier is that student controls over their Leaderboard participation. Apart from that, there are two options regarding a student's visibility on the Leaderboard:

- Top Students: Only a certain amount of top ranking students will be visible;

- Achievements, within GeNIE, are made of four components:

Signifier, Description, Completion Criteria, and Rewards. Three of these components, except rewards, are defined by Hamari and Eranti [15]. There are predefined completion criteria in the system.

\subsection{Self-determination Theory (SDT)}

Self-Determination Theory (SDT) characterizes the link between inborn inspiration and outward inspiration. It shows three essential components: Need for skill, requirement for relatedness and requirement for independence. Those three were presented in a comparative time, the users may experience strong inalienable motivation which is also an ordinary character of a self-inspiration [23].

The above two technologies are very similar to Gamification for Teaching and Learning Java Programming for Beginners Students, because both clearly show the use and role gamification plays in encouraging and motivating users. Gamification is a revolute method in the field of education and this method is gradually replacing traditional learning methods. In fact, the spread of digital technology makes gamification more practical to the new generation of digital natives accustomed to the practice of games.

\section{Conclusion}

In this paper, the researchers emphasized how gamification can help Java programming learners by removing the difficulties faced in learning like the lack of motivation or engagement. This paper helps beginner students to learn java programming by playing game which will give fun and excitement in their learning. Overall, even though this study was rather limited in terms of providing solid results, respondents were enthusiastic about the system and the idea of gamification. This further emphasizes the need for single element studies and the importance of differences between perceived and actual benefits of gamification with a strong emphasis on psychometric evaluation.

For future work, gamification components should be analyzed detail. Furthermore, all components ought to look at in the easiest frame and in addition a blend of components.

\section{References}

[1] Elshiekh, R., \& Butgerit, L. (2017). Using Gamification to Teach Students Programming Concepts, 4, 1-8.

[2] Alhammad, M. M., \& Moreno, A. M. (2018). Gamification in software engineering education: A systematic mapping. J. Syst. Softw., 141, 131-150.

[3] Fernandez, R. (2014). A Cognitive Apprenticeship Approach for Teaching Abstract and Complex Skills in an Online Learning Environment, 2.

[4] Aseriskis, D., \& Damasevicius, R. (2014). Gamification of a project management system. Proceedings of ACHI 2014 Seventh Int. Conf. Adv. Comput. Interact (pp. 200-207).

[5] Murphy, C., Kim, E., Kaiser, G., \& Cannon, A. (2008). Backstop : A Tool for Debugging Runtime Errors Backstop: A Tool for Debugging Runtime Errors.

[6] Al-azawi, Al-faliti, R., \& Al-blushi, M. (2016). Educational gamification Vs game based learning: Comparative study. Int. J. Innov. Manag. Technol., 7(4), 132-137.

[7] Sung, Y., Chang, K., \& Liu, T. (2016). Computers \& education the effects of integrating mobile devices with teaching and learning on students â€тM learning performance: A meta-analysis and research synthesis. Comput. Educ., 94, 252-275.

[8] Sailer, M., Ulrich, J., Katharina, S., \& Mandl, H. (2017). How gamification motivates: An experimental 
study of the effects of specific game design elements on psychological need satisfaction computers in human behavior how gamification motivates: An experimental study of the effects of specific game design elements on psychological need satisfaction. Comput. Human Behav., 69, 371-380.

[9] Series, C. (2018). Learning Basic Programming Using CLIS through Gamification.

[10] Singh, T. (2012). New learning methodology for student of Java programming language. Int. J. Eng. Res. Dev., 3(11).

[11] Exton, G. (2017). Gamification as a Motivational Tool for Software Systems, as Illustrated in a Second-Language Learning Environment by.

[12] Nurul, S., \& Mohamad, M. (2018). Gamification Approach in Education to Increase Learning Engagement Gamification Approach in Education to Increase Learning Engagement.

[13] Duggal, K., Srivastav, A., \& Kaur, S. (2014). Gamified approach to database normalization. Int. J. Comput. Appl., 93(4), 47-53.

[14] Profile, S. E. E. (2014). New Learning Methodology for Student of Java Programming Language Tejinder Singh.

[15] Wójcik, J. Motivation for students: Gamification in E-learning. Ue.Katowice.Pl.

[16] Çubukçu, Ç., Wang, B., Goodman, L., \& Mangina, E. (2017). Gamification for teaching Java. Proceedings of 10th EAI Int. Conf. Simul. Tools Tech. - SIMUTOOLS '17 (pp. 120-130).

[17] Nah, F. F., Zeng, Q., \& Telaprolu, V. R. Gamification of Education : A Review of Literature, 401-402.

[18] Kay, Õ., Oktekin, B., \& Hüseyin, Õ. (2016). Integration of Gamification Technology in Education, 102, 668-676.

[19] Alsawaier, R. S. (2015). The Effect of Gamification on Motivation and Engagement, 2012.

[20] De Sousa Borges, S., Durelli, V. H. S., Reis, H. M., \& Isotani, S. (2014). A systematic mapping on gamification applied to education. Proceedings of the 29th Annu. ACM Symp. Appl. Comput. - SAC '14, no. Icmc (pp. 216-222).

[21] Kasurinen, J., \& Knutas, A. (2018). Publication trends in gamification: A systematic mapping study. Comput. Sci. Rev., 27, 33-44.

[22] Gachkova, M., \& Somova, E. Game-Based Approach in E-learning, 143-152.

[23] Legault, L. (2017). Self-determination Theory, 1-9.

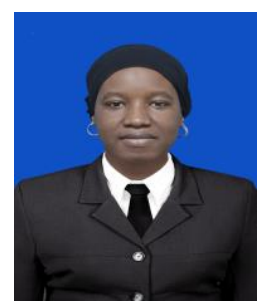

Jaouja Maiga was born in MALI. She received the bachelor's degree in computer science at Université des Sciences, des Techniques et des Technologies de Bamako (USTTB MALI) in 2014, She is currently pursuing masters of informatics engineering at Universitas Atma Jaya Yogyakarta. Her interests are mobile computing, parallel programming (CUDA), IoT focused in education field by designing the mobile application system.

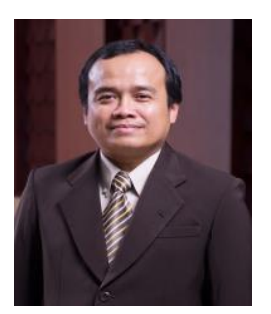

Andi Wahju Rahardjo Emanuel was born in Klaten, Central Java, Indonesia in 1972. He received his BSEE degree from Purdue University, USA in 1996, MSSE from the University of Melbourne, Australia in 2001, and doctorate degree in computer science from Universitas Gadjah Mada, Indonesia in 2012.

Currently, he is full time lecturer at Universitas Atma Jaya Yogyakarta. His research interest include software engineering, software quality, software metrics, and knowledge discovery. 